\title{
Methotrexate in combination with other DMARDs is not superior to methotrexate alone for remission induction with moderate-to-high-dose glucocorticoid bridging in early rheumatoid arthritis after 16 weeks of treatment: the CareRA trial
}

\author{
P Verschueren, ${ }^{1,2}$ D De Cock, ${ }^{1}$ L Corluy, ${ }^{3,4}$ R Joos $^{5}$ C Langenaken, $^{3,4}$ V Taelman, ${ }^{6}$ \\ F Raeman, ${ }^{5}$ I Ravelingien, ${ }^{7}$ K Vandevyvere, ${ }^{8}$ J Lenaerts, ${ }^{3,4}$ E Geens, $^{5}$ P Geusens, ${ }^{9}, 10$ \\ J Vanhoof, ${ }^{9}$ A Durnez, ${ }^{8}$ J Remans, ${ }^{11}$ B Vander Cruyssen, ${ }^{7}$ E Van Essche, ${ }^{12}$ \\ A Sileghem, ${ }^{13} \mathrm{G}$ De Brabanter, ${ }^{14} \mathrm{~J} \mathrm{Joly}^{2}{ }^{2} \mathrm{~S}$ Meyfroidt, ${ }^{1} \mathrm{~K}$ Van der Elst, ${ }^{2,15}$ \\ $\mathrm{R}$ Westhovens ${ }^{1,2}$
}

\begin{abstract}
Handling editor Tore K Kvien
- Additional material is published online only. To view please visit the journal online (http://dx.doi.org/10.1136/ annrheumdis-2014-205489)
\end{abstract}

For numbered affiliations see end of article.

Correspondence to D De Cock, Skeletal Biology and Engineering Research

Center, KU Leuven Department of Development and

Regeneration, Herestraat 49, Leuven 3000, Belgium; diederik.decock@med. kuleuven.be

PV and DDC are co-first authors.

Received 28 February 2014 Revised 6 October 2014 Accepted 12 October 2014 Published Online First 30 October 2014

\section{CrossMark}

To cite: Verschueren $P$, De Cock D, Corluy L, et al. Ann Rheum Dis 2015:74:27-34.

\section{ABSTRACT}

Objectives To compare the efficacy and safety of intensive combination strategies with glucocorticoids (GCs) in the first 16 weeks (W) of early rheumatoid arthritis (eRA) treatment, focusing on high-risk patients, in the Care in early RA trial.

Methods 400 disease-modifying antirheumatic drugs (DMARD)-naive patients with eRA were recruited and stratified into high risk or low risk according to classical prognostic markers. High-risk patients $(n=290)$ were randomised to $1 / 3$ treatment strategies: combination therapy for early rheumatoid arthritis (COBRA) Classic (methotrexate (MTX)+ sulfasalazine+60 mg prednisone tapered to $7.5 \mathrm{mg}$ daily from W7), COBRA Slim (MTX $+30 \mathrm{mg}$ prednisone tapered to $5 \mathrm{mg}$ from W6) and COBRA Avant-Garde (MTX+leflunomide+30 mg prednisone tapered to $5 \mathrm{mg}$ from W6). Treatment modifications to target low-disease activity were mandatory from W8, if desirable and feasible according to the rheumatologist. The primary outcome was remission (28 joint disease activity score calculated with C-reactive protein $<2.6$ ) at W16 (intention-to-treat analysis). Secondary endpoints were good European League Against Rheumatism response, clinically meaningful health assessment questionnaire (HAQ) response and $\mathrm{HAQ}$ equal to zero. Adverse events (AEs) were registered.

Results Data from 98 Classic, 98 Slim and 94 AvantGarde patients were analysed. At W16, remission was reached in $70.4 \%$ Classic, $73.6 \%$ Slim and $68.1 \%$ Avant-Garde patients ( $p=0.713$ ). Likewise, no significant differences were shown in other secondary endpoints. However, therapy-related AEs were reported in $61.2 \%$ of Classic, in $46.9 \%$ of Slim and in $69.1 \%$ of Avant-Garde patients ( $p=0.006$ ).

Conclusions For high-risk eRA, MTX associated with a moderate step-down dose of GCs was as effective in inducing remission at W16 as DMARD combination therapies with moderate or high step-down GC doses and it showed a more favourable short-term safety profile. EudraCT number: 2008-007225-39.

\section{INTRODUCTION}

While in the past patients with early rheumatoid arthritis (eRA) were treated conservatively, current guidelines recommend treating high-risk patients intensively, early and to target. ${ }^{1-3} \mathrm{~A}$ lot of interesting and important pioneering work has already been done, but many questions regarding the optimal dosage and combination of medication in the management of patients with eRA remain unaddressed. ${ }^{4}$

Trials using early intensive combination strategies with classical disease-modifying antirheumatic drugs (DMARDs) and glucocorticoids (GCs) gave rise to the 'early window of opportunity' theory. ${ }^{5-10}$ This implies that if intensive treatment is initiated early in the disease process and disease activity is rapidly controlled, more patients will go into long-term remission with better functional and radiographic outcomes later on. ${ }^{11-16}$ Discussion still exists about the optimal way to rapidly induce remission at the individual patient level. Some patients might do equally well on methotrexate (MTX) monotherapy, and even in case of insufficient response, intensifying to triple DMARD therapy or a combination with a biological can rescue patients later on. ${ }^{17} \mathrm{~A}$ delay in optimal disease control might indeed not necessarily result in worse outcomes at standard evaluation time points, but unfortunately does not take into account the cumulative disease activity patients have to suffer before arriving at these endpoints. This illustrates that the patient perspective is still understudied in traditional eRA trials.

Guidelines suggest adapting treatment according to prognostic factors. ${ }^{1-3}$ Unfortunately, this does not guarantee a favourable outcome in daily practice. ${ }^{18}$ Until better prediction models become available, the most effective approach to use the window of opportunity is to combine classical DMARDs with rapid remission inducing agents like GCs or biologicals.

GCs are commonly used to bridge the onset of the therapeutic effect of DMARDs, to rapidly control inflammation and to prevent radiographic damage. ${ }^{19-21}$ During the difficult initial treatment 
weeks, GCs can relieve pain, stiffness and disability, allowing patients to take up again their role in society more rapidly and potentially preventing chronic disease behaviour. The perception on GCs, however, remains ambiguous in both the patient's and the physician's mind. Thus many rheumatologists hesitate to prescribe GCs due to fear for side effects. ${ }^{22} 23$ Little is yet known about the optimal initial dose, treatment duration and administration route. ${ }^{24}$

Ample evidence indicates that compared with MTX monotherapy, biologicals combined with MTX are more efficacious in eRA. Unfortunately, insufficient clarity exists whether these agents can be used as remission induction agents in bridging strategies just as well as GCs since most trial protocols led to persistent biological use after the induction phase. $.^{8} \quad 25-27$ Moreover, tumour necrosis factor-blocking agents did not demonstrate superior efficacy compared with induction regimes with GCs. ${ }^{28}$ Thus, administering GCs could avoid or postpone starting expensive long-term biological therapy. ${ }^{29}$

The debate on the ideal DMARD content of initial RA treatment strategies is still ongoing. ${ }^{30} 31$ Triple therapy (MTX, sulfasalazine (SSZ) and hydroxychloroquine), combination therapy for early rheumatoid arthritis (COBRA)-like schemes (MTX \pm SSZ+ GCs) or other DMARD combination therapies show excellent clinical efficacy compared with monotherapy. ${ }^{5-8} \quad 17 \quad 32-37$ However, studies comparing different intensive treat-to-target regimens of classical DMARDs associated with a remissioninducing agent are scarce.

The aim of the current study was to compare in high-risk patients with eRA the efficacy and safety of different initial DMARD combinations and GC bridging schemes, 16 weeks after initiation.

\section{PATIENTS AND METHODS}

\section{The CareRA study}

Care in early RA (CareRA-EudraCT number: 2008-007225-39) is a prospective 2-year investigator-initiated multicentre randomised controlled trial rooted in daily practice. The trial is conducted in 13 Flemish rheumatology centres: two academic centres, seven general hospitals and four private practices.

\section{Patients}

Patients with RA, as defined by the American College of Rheumatology 1987 revised criteria, were recruited between
January 2009 and May 2013. The main inclusion criteria were having a disease duration $\leq 1$ year and being DMARD and GCs treatment naive. Disease duration was defined as time elapsed between RA diagnosis and treatment initiation. Patients having contraindications for intensive treatment combinations with GCs as judged by the treating rheumatologist were excluded. See online supplement 1 for a full list of exclusion criteria.

Patients were allocated to a high-risk group based on an algorithm constructed with classical RA prognostic factors: erosions, rheumatoid factor (RF) and/or anticitrullinated protein antibody (ACPA) and disease activity score based on C-reactive protein (CRP) status (DAS28 (CRP)) at screening (figure 1).

\section{Design}

After risk allocation, high-risk patients were randomised into 1/3 treatment arms:

- COBRA Classic: 15 mg MTX weekly, 2 g SSZ daily and a weekly step-down scheme of oral GCs (60-40-25-20-15-10-7.5 mg prednisone). This scheme has a higher dose of MTX than the original cobra schedule, based on experience in daily clinical practice. ${ }^{5} 35$

- COBRA Slim: 15 mg MTX weekly with a weekly step-down scheme of oral GCs (30-20-12.5-10-7.5-5 mg prednisone).

- COBRA Avant-Garde: 15 mg MTX weekly, $10 \mathrm{mg}$ leflunomide (LEF) daily and a weekly step-down scheme of oral GCs (30-20-12.5-10-7.5-5 mg prednisone).

The GC dose was tapered down weekly except for the lowest dose (7.5 mg in COBRA Classic and $5 \mathrm{mg}$ in the other arms), which was maintained until week (W) 28. Then, GCs were tapered on a weekly basis by leaving out one daily dose each week over a period of 6 weeks until complete discontinuation. Prophylactic treatment including oral folic acid, calcium and vitamin D supplements was prescribed to all patients. Furthermore, all patients received face-to-face education and info-material (leaflet, DVD and website) about the disease as well as on the proposed treatment at screening. Additional information was given on demand.

A treat-to-target approach was used in a tight control setting, ${ }^{38}$ aiming for a DAS28(CRP) $\leq 3.2 .{ }^{39}$ If patients failed to reach this target, treatment adjustments were made according to protocol from W8 onwards. Treating rheumatologists had the option not to adapt treatment, but in that case they had to motivate their decision based on a predefined list of specific clinical

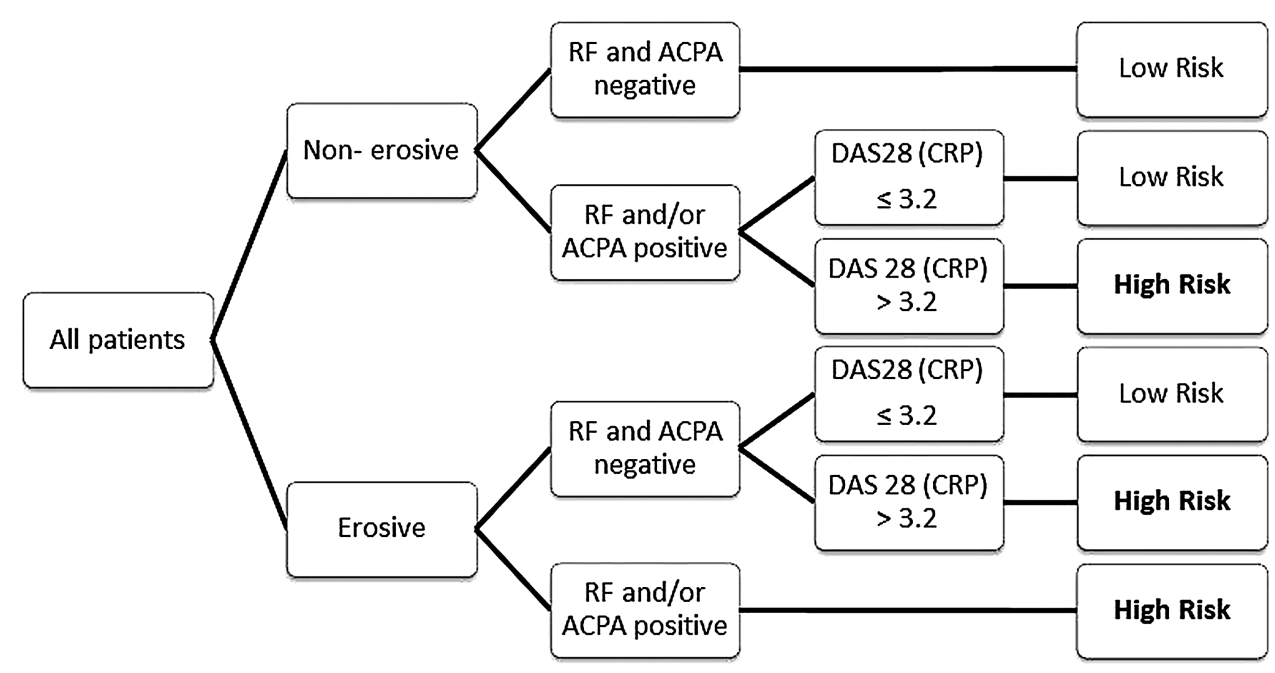

Figure 1 Classification of patients in high or low risk according to classic prognostic factors. ACPA, anticitrullinated protein antibody; DAS28 (CRP), 28 joint disease activity score calculated with C-reactive protein; RF, rheumatoid factor. 
conditions. Other treatment adjustments not stated in the protocol could not be implemented by the treating physician. The first adjustment in all treatment arms was a weekly increase in MTX dose to $20 \mathrm{mg}$. If necessary a second adjustment could be made from 8 weeks after the first adjustment. The second adjustment depended on the treatment arm: an SSZ dose increase to $3 \mathrm{~g}$ daily in COBRA Classic, an LEF addition of $10 \mathrm{mg}$ daily in COBRA Slim or an LEF dose increase to $20 \mathrm{mg}$ daily in COBRA Avant-Garde. If patients did not reach the target after two predefined treatment adjustments during the first year, this was considered a strategy failure for efficacy reasons.

Intramuscular and intra-articular GC injections were allowed maximally every 8 weeks, but not within 4 weeks preceding W16. Concomitant therapy with non-steroidal antiinflammatory drugs and analgesics was allowed and registered.

\section{Assessment}

Patients were assessed at screening, baseline, W4, W8 and W16. A maximum of 4 weeks were allowed between screening and baseline. In case a treatment adjustment was required according to the protocol at W8, an optional visit was performed at W12. Demographics were registered at screening and clinical parameters, DAS28(CRP) and health assessment questionnaire (HAQ) at every visit (table 1).

\section{Safety and toxicity}

At each visit, patients were asked about any adverse events (AE) and medication changes. Each reported $\mathrm{AE}$ was registered and evaluated in relation to therapy, seriousness and severity by the treating rheumatologist. In case of toxicity, the protocol predefined schemes for tapering/interrupting the assigned treatment strategy. If toxicity was persistent, this was considered a strategy failure for safety reasons.

\section{Outcomes}

The primary outcome of this study was the proportion of patients in remission (DAS28 $(\mathrm{CRP})<2.6)$ at W16. Secondary outcomes were the proportion of good European League Against Rheumatism (EULAR) responders (DAS28(CRP) change $>1.2$ and DAS28(CRP) $\leq 3.2$ ), the proportion of patients having a clinically meaningful improvement of the HAQ (HAQ change $>0.22$ ) and the proportion of patients having an HAQ equal to zero at W16.

\section{Statistical analysis}

The study was designed as a superiority analysis of Classic versus Slim and Avant-Garde versus Slim. Sample-size calculation was based upon the proportion of patients in remission at W16. Eighty-five patients per treatment arm were required for a power of $80 \%$ and significance level of 0.05 , starting from an estimated clinically relevant difference in effect size of $20 \%$. All patients starting treatment were analysed.

Missing data were handled as follows. Screening variables were used to impute missing baseline variables and vice versa. A maximum likelihood model (by the Expectation-Maximisation algorithm) was applied to impute missing data needed to calculate the DAS28(CRP) at W4, W8 and W16.

An intention-to-treat analysis was performed by $\chi^{2}$ or Kruskal-Wallis test, when appropriate. Area under the curve (AUC) analysis was used to evaluate the DAS28(CRP) over time. All statistical analyses were carried out using the Statistical Package for the Social Sciences (SPSS) V.20. A p value $<0.05$ was considered statistically significant.
Table 1 Patients' characteristics at baseline per treatment arm

\begin{tabular}{|c|c|c|c|}
\hline & $\begin{array}{l}\text { COBRA } \\
\text { Classic }\end{array}$ & $\begin{array}{l}\text { COBRA } \\
\text { Slim }\end{array}$ & $\begin{array}{l}\text { COBRA } \\
\text { Avant-Garde }\end{array}$ \\
\hline Number of patients & 98 & 98 & 94 \\
\hline Age (years) & $53.2 \pm 11.9$ & $51.8 \pm 13.1$ & $51.2 \pm 12.8$ \\
\hline BMI $\left(\mathrm{kg} / \mathrm{m}^{2}\right)$ & $26.0 .99 \pm 4.3$ & $26.8 \pm 4.2$ & $26.5 \pm 4.2$ \\
\hline Gender (women) & $65.3 \%$ & $64.3 \%$ & $69.1 \%$ \\
\hline Smoking status (ever) & $57.1 \%$ & $59.2 \%$ & $60.6 \%$ \\
\hline Alcohol intake (yes) & $55.1 \%$ & $56.1 \%$ & $54.3 \%$ \\
\hline Symptom duration (weeks) & $33.8 \pm 35.5$ & $33.2 \pm 38.2$ & $44.2 \pm 65.6$ \\
\hline Disease duration (weeks) & $1.8 \pm 3.1$ & $2.6 \pm 3.3$ & $3.1 \pm 6.3$ \\
\hline $\begin{array}{l}\text { Employed before symptom } \\
\text { onset (yes) }\end{array}$ & $52.0 \%$ & $65.3 \%$ & $62.8 \%$ \\
\hline Employed at screening (yes) & $44.9 \%$ & $53.1 \%$ & $51.1 \%$ \\
\hline Comorbidities at screening (yes) & $72.4 \%$ & $74.5 \%$ & $64.9 \%$ \\
\hline Nocturnal pain (yes) & $69.4 \%$ & $72.4 \%$ & $68.1 \%$ \\
\hline Morning stiffness (yes) & $74.5 \%$ & $68.4 \%$ & $58.4 \%$ \\
\hline RF (yes) & $79.6 \%$ & $83.7 \%$ & $75.5 \%$ \\
\hline ACPA (yes) & $77.6 \%$ & $79.6 \%$ & $77.7 \%$ \\
\hline Erosions (yes) & $32.7 \%$ & $32.7 \%$ & $34.0 \%$ \\
\hline Total TJC & $14.7 \pm 9.5$ & $13.7 \pm 8.2$ & $14.0 \pm 9.0$ \\
\hline Total SJC & $11.9 \pm 8.9$ & $10.8 \pm 6.5$ & $10.5 \pm 6.8$ \\
\hline TJC28 & $9.5 \pm 6.0$ & $8.5 \pm 5.5$ & $8.2 \pm 5.5$ \\
\hline SJC28 & $7.9 \pm 6.0$ & $7.1 \pm 4.6$ & $7.0 \pm 5.1$ \\
\hline PGA (0-100) & $59.5 \pm 21.7$ & $56.2 \pm 21.7$ & $54.5 \pm 24.3$ \\
\hline Pain $(0-100)$ & $59.5 \pm 23.6$ & $56.5 \pm 21.9$ & $56.9 \pm 23.88$ \\
\hline Fatigue $(0-100)$ & $50.6 \pm 26.0$ & $49.0 \pm 21.3$ & $48.68 \pm 23.78$ \\
\hline PhGA $(0-100)$ & $54.7 \pm 18.5$ & $53.1 \pm 18.1$ & $51.8 \pm 18.2$ \\
\hline ESR & $33.59 \pm 25.2$ & $32.1 \pm 23.3$ & $25.18 \pm 17.7$ \\
\hline CRP & $19.7 \pm 28.9$ & $21.5 \pm 33.3$ & $15.1 \pm 20.0$ \\
\hline DAS28(ESR) & $5.4 \pm 1.3$ & $5.2 \pm 1.2$ & $5.0 \pm 1.3$ \\
\hline DAS28(CRP) & $5.0 \pm 1.2$ & $4.9 \pm 1.1$ & $4.7 \pm 1.2$ \\
\hline HAQ (0-3) & $1.2 \pm 0.7$ & $0.98 \pm 0.69$ & $0.99 \pm 0.64$ \\
\hline
\end{tabular}

ACPA, anticitrullinated protein antibody; BMI, body mass index; CRP, C-reactive protein; DAS28, 28 joint disease activity score; Disease duration, time elapsed between diagnosis of RA and start of treatment; ESR, erythrocyte sedimentation rate; $H A Q$, health assessment questionnaire; Morning stiffness, being stiff in the morning for at least $45 \mathrm{~min}$; PGA, patient global assessment; PhGA, physician global assessment; RF, rheumatoid factor; SJC, swollen joint count; Symptom duration, time elapsed between onset of symptoms and start of treatment; TJC, tender joint count; COBRA, combination therapy for early rheumatoid arthritis.

Data are presented as mean \pm SD or as percentages.

\section{RESULTS}

A total of 400 patients were screened and 380 patients were included in CareRA. Seventy-five per cent of these patients were included in non-university centres. No differences in demographic and clinical characteristics were observed between screened and included patients. In total, 290 patients were allocated to the high-risk group and randomly assigned to treatment in the COBRA Classic (98), COBRA Slim (98) and COBRA Avant-Garde (94) arm. Randomisation resulted in similar baseline characteristics between groups (table 1 ).

Figure 2 describes the patient disposition from screening until W16.

\section{Efficacy}

Primary outcome

Remission was achieved in $70.4 \%$ (68/98) COBRA Classic patients, 73.5\% (72/98) COBRA Slim patients and 68.1\% (64/94) COBRA Avant-Garde patients $(\mathrm{p}=0.713)$ at W16 (figure $3 \mathrm{~A})$.

\section{Secondary outcomes}

At W16, a good EULAR response was reached in $79.6 \%$ of Classic patients, $79.6 \%$ of Slim patients and $76.6 \%$ of 
Figure 2 Patient disposition flow chart.

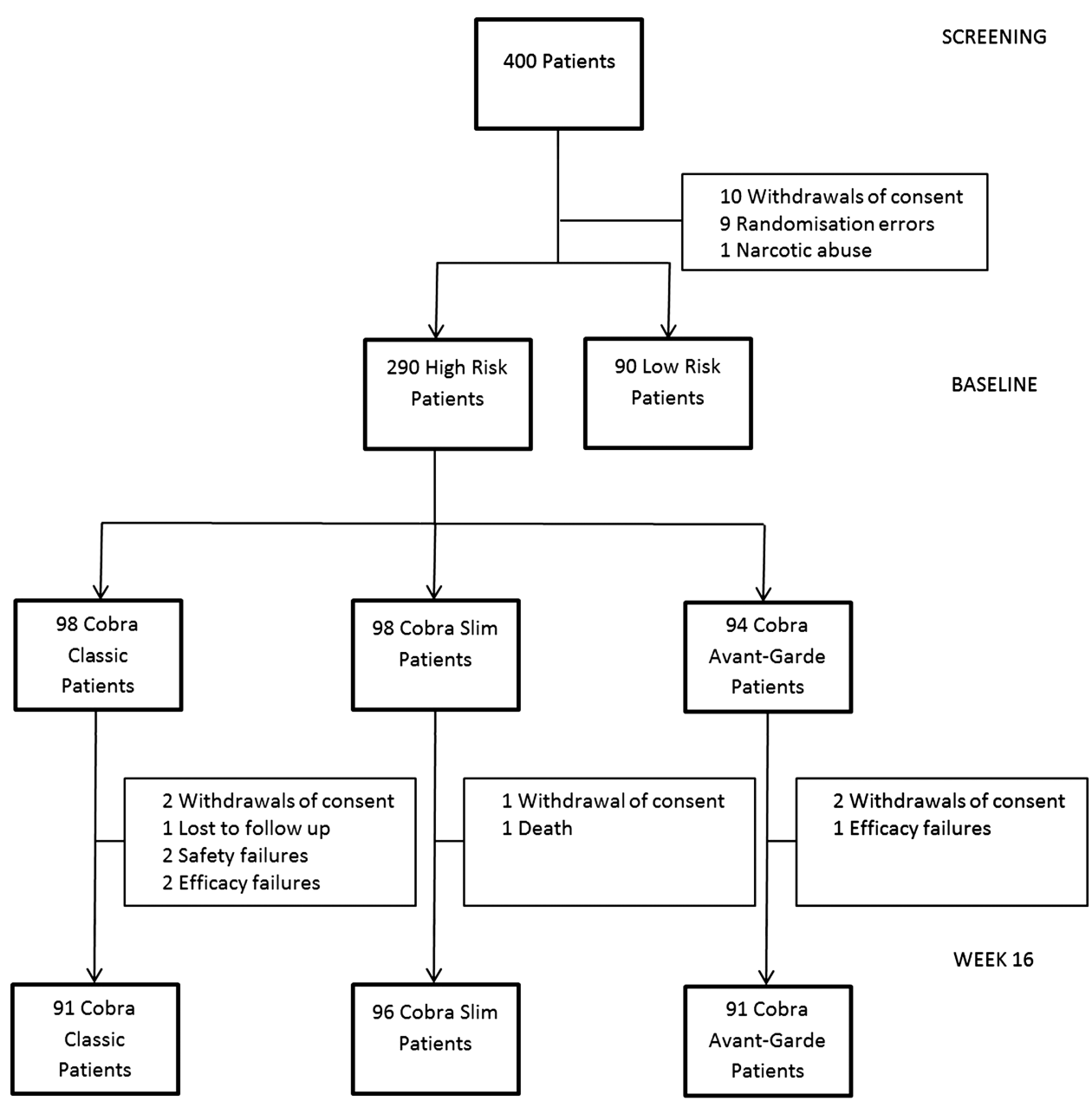

Avant-Garde patients $(\mathrm{p}=0.844)$. A clinically meaningful HAQ response was reached in $84.7 \%$ of Classic patients, $86.7 \%$ of Slim patients and $76.6 \%$ of Avant-Garde patients $(p=0.271)$. HAQ was equal to zero in $45.9 \%$ of Classic patients, $42.9 \%$ of Slim patients and $48.9 \%$ of Avant-Garde patients $(p=0.700)$ (table 2).

Likewise, complete case analysis (without missing data imputation) of the primary and secondary outcomes revealed no significant differences between the three treatment arms (data not shown).

\section{Area under the curve}

The mean \pm SD AUC for DAS28(CRP) from baseline to W16 was $10.66 \pm 3.41,11.05 \pm 3.39$ and $10.72 \pm 2.96$ for the Classic, Slim and Avant-Garde, respectively $(p=0.521)$ (figure 3B).

\section{Treatment adaptations according to protocol}

During the first 16 weeks of therapy, treatment adaptations were performed in 19.4\%, 22.4\% and 14.9\% in the Classic, Slim and Avant-Garde arm, respectively $(\mathrm{p}=0.407)$. Of these patients requiring treatment adaptations at $\mathrm{W} 8,50.0 \%, 87.5 \%$ and $60.0 \%$ in the Classic, Slim and Avant-Garde arm, respectively, reached the low-disease activity target at W16 $(\mathrm{p}=0.086)$. Of 61 patients requiring per protocol treatment adaptation at W8, $39 \%(24 / 61)$ had no change in therapy because of contraindications or because the treating physician judged the disease sufficiently controlled. These 24 patients received no other medication and stayed on the initial strategy without treatment adaptation. Intra-articular GC injections were given in 3.1\% of Classic patients, $5.1 \%$ of Slim patients and $5.1 \%$ of Avant-Garde patients $(\mathrm{p}=0.703)$.

\section{Safety}

Therapy-related AEs were registered in 171 out of the 290 patients $(59 \%)$ during the first 16 weeks of treatment. These were reported in $61.2 \%$ of Classic, in $46.9 \%$ of Slim and in $69.1 \%$ of Avant-Garde patients $(\mathrm{p}=0.006)$. The total number of AEs related to Classic, Slim and Avant-Garde treatment was 148,70 and 130 , respectively, with a similar distribution for discomfort and toxicity (table 3 ).

\section{DISCUSSION}

In patients with eRA with unfavourable classical prognostic factors such as RF, ACPA, erosions and/or high-disease activity, MTX associated with a moderate step-down dose of GCs was as effective as DMARD combination therapies with moderate or high step-down GC doses, for remission induction at 16 weeks. Furthermore, the short-term safety profile of MTX associated with a moderate step-down dose of GCs was more favourable.

This finding has two implications. First, in association with a moderate or high GC dose, the combination of MTX with other DMARDs does not seem to be more effective compared with MTX alone, at least in the early treatment stage. Until now only a few studies have addressed the question whether DMARD combinations are superior to MTX monotherapy independent from additional GC bridging in eRA. ${ }^{32-34}$ The 
A

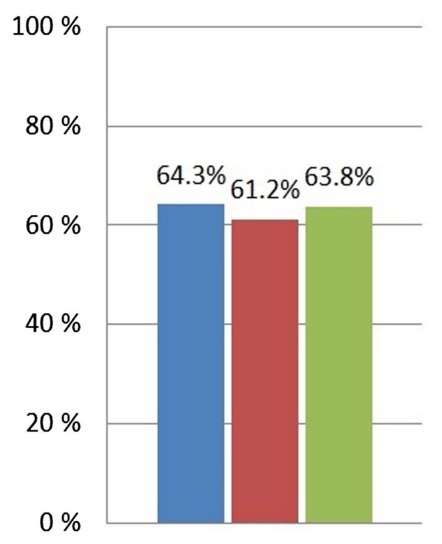

Week 8

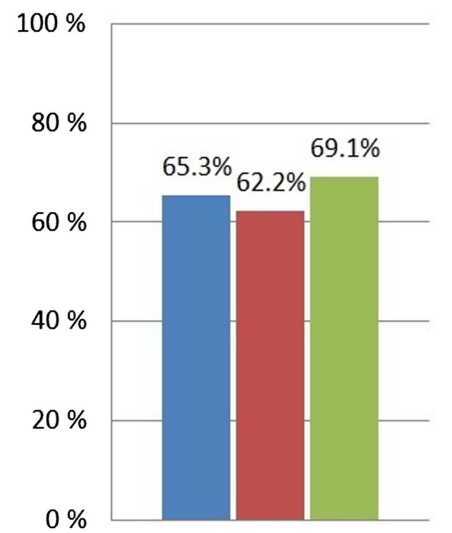

Week 16

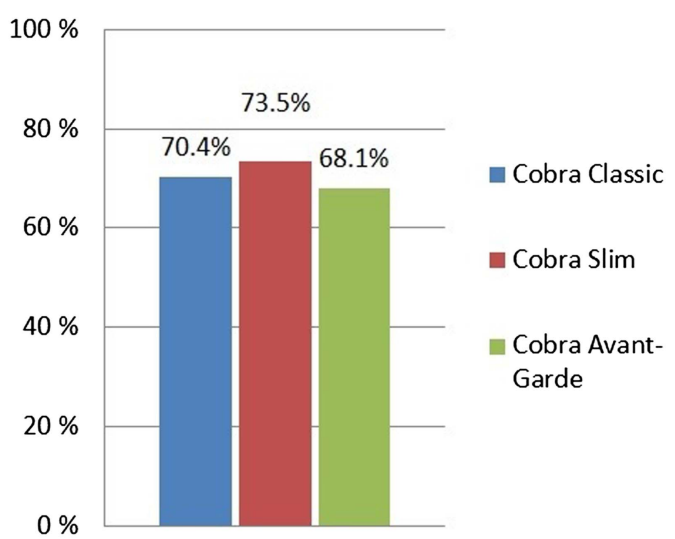

\begin{tabular}{|l|l|l|l|l|}
\hline & Cobra Classic & Cobra Slim & Cobra Avant-Garde & p-value \\
\hline & 98 & 98 & 94 & \\
\hline W4 & $63(64.3 \%)$ & $60(61.2 \%)$ & $60(70.4 \%)$ & 0.892 \\
\hline W8 & $64(65.3 \%)$ & $61(62.2 \%)$ & $65(73.5 \%)$ & 0.602 \\
\hline W16 & $69(70.4 \%)$ & $72(73.5 \%)$ & $64(68.1 \%)$ & 0.713 \\
\hline
\end{tabular}

Remission was defined as DAS28(CRP) <2.6; DAS28(CRP) $=28$ Joint disease activity score calculated with C-reactive protein. The proportion of patients per treatment arm was compared via $\chi^{2}$ testing and no statistically significant differences were found.

B The evolution of DAS28(CRP) from baseline to W16

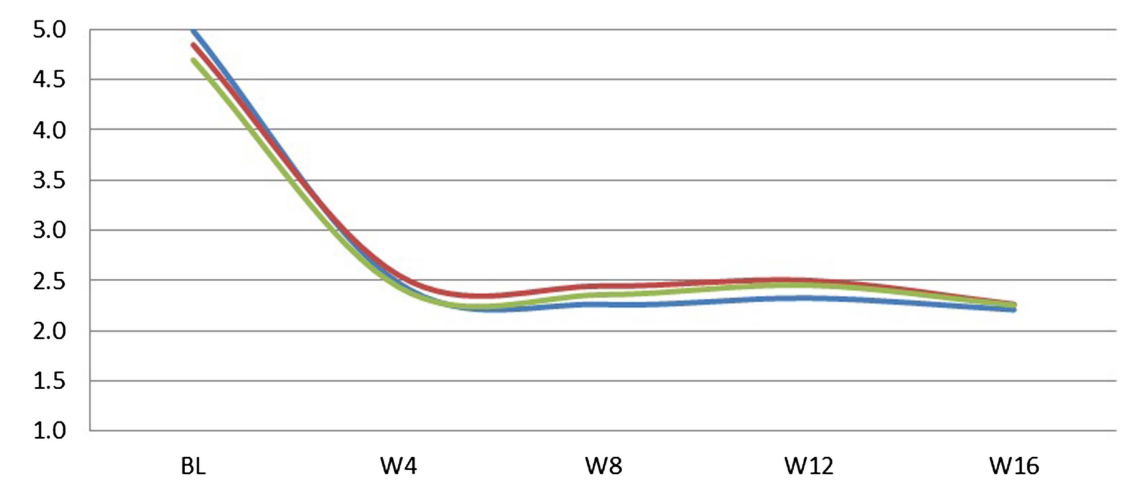

Figure 3 Remission and disease activity over 16 weeks. (A) The proportion of patients in remission per treatment arm at weeks 4, 8 and 16 . (B) The area under the curve of DAS28(CRP) per treatment arm during 16 weeks of treatment. DAS28(CRP), 28 joint disease activity score calculated with C-reactive protein.

tREACH trial showed that DMARD combination was better than MTX monotherapy, both in association with low-dose GC bridging. In our trial, the COBRA-like moderate-dose or highdose GC scheme bridged the time lag before full DMARD efficacy, probably erasing any difference between the different DMARD schedules. As a consequence, less medication is needed over time, which might impact $\mathrm{AE}$ and possibly also patients' adherence to treatment. The tight control setting could also correct swiftly for any suboptimal treatment regimen, explaining some of the good efficacy of COBRA Slim. However, only MTX dose adjustment and no step up to combination therapy could be implemented before W16. Furthermore, the proportion of treatment adjustments between the three arms was not significantly different.

Second, a high-dose GC scheme starting at $60 \mathrm{mg}$ prednisone does not seem to improve early clinical outcomes compared with a moderate-dose scheme starting at $30 \mathrm{mg}$ prednisone, regardless of the DMARD strategy used. Thus, a lower cumulative GC dose is still equally effective, perhaps avoiding longterm AEs. Furthermore, the possibility to use a lower dose of GCs, while having the same efficacy, could benefit the implementation of COBRA-like strategies. Rheumatologists appear more reluctant to administer complex therapies with high dosages of GCs, 22 23 40-42 although we showed that this approach is feasible in daily practice. ${ }^{35}$ den Uyl et $a l^{36}$ reported similar results comparing an attenuated COBRA regimen with the original one in a moderately active eRA population. However, this study lacked decisive evidence, the MTX dose in the classical scheme was suboptimal and the GC scheme in the attenuated COBRA version was cumulatively comparable with the classical one.

Many rheumatologists use low-dose GCs in association with DMARDS for eRA in daily practice, much to their own and their patients' satisfaction. They have, however, doubts about 
Table 2 Clinical outcomes at week 16 per treatment arm

\begin{tabular}{|c|c|c|c|c|c|c|}
\hline & COBRA Classic & COBRA Slim & $\begin{array}{l}\text { COBRA } \\
\text { Avant-Garde }\end{array}$ & p Value & $\begin{array}{l}\Delta \text { between Classic } \\
\text { vs Slim }(95 \% \mathrm{Cl})\end{array}$ & $\begin{array}{l}\Delta \text { between Avant-Garde } \\
\text { vs Slim }(95 \% \mathrm{Cl})\end{array}$ \\
\hline Number of patients & 98 & 98 & 94 & & & \\
\hline DAS28 (CRP) change & $2.8 \pm 1.2$ & $2.6 \pm 1.2$ & $2.4 \pm 1.3$ & 0.140 & $0.2(-0.13$ to 0.52$)$ & $-0.2(-0.49$ to 0.21$)$ \\
\hline Remission & $70.4 \%$ & $73.5 \%$ & $68.1 \%$ & 0.713 & $-3.1 \%(-15.4 \%$ to $9.5 \%)$ & $-5.4 \%(-18.0 \%$ to $7.4 \%)$ \\
\hline Low-disease activity & $84.7 \%$ & $86.7 \%$ & $87.2 \%$ & 0.863 & $-2.0 \%(-12.0 \%$ to $7.9 \%)$ & $0.5 \%(-9.3 \%$ to $10.2 \%)$ \\
\hline Good EULAR response & $79.6 \%$ & $79.6 \%$ & $76.6 \%$ & 0.844 & $0.0 \%(-11.3 \%$ to $11.3 \%)$ & $-3.0 \%(-14.7 \%$ to $8.7 \%)$ \\
\hline Moderate EULAR response & $98.0 \%$ & $95.9 \%$ & $93.6 \%$ & 0.320 & $2.1 \%(-3.6 \%$ to $8.2 \%)$ & $-2.3 \%(-9.6 \%$ to $4.6 \%)$ \\
\hline HAQ change & $0.8 \pm 0.6$ & $0.6 \pm 0.6$ & $0.7 \pm 0.6$ & 0.081 & $0.2(0.02$ to 0.37$)$ & $0.1(-0.17$ to 0.19$)$ \\
\hline Clinically meaningful HAQ change & $84.7 \%$ & $76.5 \%$ & $76.6 \%$ & 0.271 & $8.2 \%(-3.0 \%$ to $19,1 \%)$ & $0.1 \%(-11.9 \%$ to $12.0 \%)$ \\
\hline $\mathrm{HAQ}=0$ & $45.9 \%$ & $42.9 \%$ & $48.9 \%$ & 0.700 & $3.0 \%(-10.7 \%$ to $16.6 \%)$ & $6.0 \%(-7.9 \%$ to $19.7 \%)$ \\
\hline
\end{tabular}

the need for higher GC dosages and prolonged use. The potential advantage of a COBRA-like schedule over low-dose GCs is two-sided. First, a high or moderate dose could have a more radical biological effect on the disease process favouring 'real' remission induction. ${ }^{43}$ Low-dose GCs show only a slow genomic effect, while higher dosages show both slow genomic and faster non-genomic effects. ${ }^{44} 45$ Second, compared with using GCs only short term and discontinuously, it can be more effective to bridge systematically the entire time window before maximum DMARD efficacy, taking up to 6 months. ${ }^{46-48}$ DMARD combinations could therefore have a short-lived advantage over DMARD monotherapy in trials using GCs not systematically, at a too low dose or for a too short period of time. ${ }^{32} 333746$

The analysis of the AUC of disease activity reinforced the study findings at every visit, illustrating that the disease burden was the same during the first 16 weeks of treatment over the three treatment arms. A delayed targeted therapy as proposed by others ${ }^{17}$ would result in a much higher cumulative disease activity. This study only presents the first 16 weeks of the CareRA trial, but this initial treatment period, the so-called

Table 3 Number of adverse events per treatment arm during 16 weeks of treatment

\begin{tabular}{lccc}
\hline & COBRA Classic & COBRA Slim & COBRA Avant-Garde \\
\hline Number of patients & 91 & 96 & 91 \\
AE related to therapy & 148 & 70 & 130 \\
Type related AE & & & \\
Discomfort & 111 & 50 & 96 \\
Toxicity & 27 & 10 & 23 \\
Infection & 5 & 3 & 5 \\
Others & 4 & 7 & 6 \\
Surgery & 1 & 0 & 0 \\
Severity of related AE & & & \\
Mild & 121 & 64 & 103 \\
Moderate & 23 & 5 & 21 \\
Severe & 4 & 1 & 6 \\
Serious AE & 2 & 1 & 3 \\
\hline AE, adverse event; COBRA, combination therapy for early rheumatoid arthritis.
\end{tabular}

'window of opportunity', is crucial for longer-term outcome at the biological and probably also at a psychosocial level. ${ }^{15} 49$ Long-term disease control and patient-reported outcomes after 1 and 2 years are awaited in CareRA.

The safety analysis strengthened the efficacy outcomes further. The proportion and number of related AEs was comparable in Classic and Avant-Garde, while Slim patients had half the related AEs. GC dosage does not make any difference in the frequency or type of related AEs at this stage. Remarkable are the comparable number of AEs of the combination therapies with different GC dose, underscoring again the prejudice against GC dosage and lack of knowledge of GC side effects.

The first two limitations are related to the design of this study, although unavoidable in a pragmatic trial aiming to reflect daily clinical practice. First, medication adherence was not measured. However, if adherence was lower in a certain trial arm, the same could be expected from this treatment regimen in daily clinical practice. Second, no blinding was implemented. Rheumatologists could have been biased towards a certain therapy and therefore report less therapy-related AEs. Certain patients could also be more motivated for certain treatment regimens than for others.

Another limitation was the superiority design of this study. We opted for this design because in a non-inferiority trial the number of patients needed would be doubled. Hence, we can only state that COBRA Classic and COBRA Avant-Garde are non-superior to COBRA Slim, which is not the same as claiming non-inferiority.

In conclusion, the data presented are positioning classical MTX therapy with bridging GCs at a lower dose than in the original COBRA study as a highly effective and safe remission induction therapy in more than $70 \%$ of high-risk patients with eRA and this in a close to daily practice setting applying a treat-to-target strategy.

\section{Author affiliations}

${ }^{1}$ Skeletal Biology and Engineering Research Center, KU Leuven Department of Development and Regeneration, Leuven, Belgium

${ }^{2}$ Department of Rheumatology, University Hospitals Leuven, Leuven, Belgium

${ }^{3}$ Reuma-instituut Hasselt, Hasselt, Belgium

${ }^{4}$ Jessa Ziekenhuis Hasselt, Hasselt, Belgium

${ }^{5}$ ZNA Jan Palfijn Antwerpen, Antwerpen, Belgium

${ }^{6}$ Heilig Hart Ziekenhuis Leuven, Leuven, Belgium 
${ }^{7}$ Department of Rheumatology, Onze-Lieve-Vrouw Ziekenhuis Aalst, Aalst, Belgium

${ }^{8}$ AZ Groeninge Hospital Kortrijk, Kortrijk, Belgium

${ }^{9}$ ReumaClinic Genk \& UHasselt, Hasselt, Belgium

${ }^{10}$ Maastricht UMC, Maastricht, the Netherlands

${ }^{11}$ Reuma-instituut Genk, Genk, Belgium

${ }^{12}$ Imeldaziekenhuis Bonheiden, Bonheiden, Belgium

${ }^{13}$ ReumaClinic Hasselt, Hasselt, Belgium

${ }^{14}$ AZ Sint Lucas Brugge, Brugge, Belgium

${ }^{15}$ Skeletal Biology and Engineering Research Center, KU Leuven Department of

Public Health and Primary Care, Leuven, Belgium

Acknowledgements We thank Veerle Stouten, Sylvie Van Vlasselaer and all other study personnel, and show our gratitude to all participating patients.

Collaborators On behalf of the CareRA study group: B Maeyaert; G De Brabanter; M Devinck; C Langenaken; J Lenaerts; L Corluy; J Remans; B Vander Cruyssen; I Ravelingien; E Van Essche; K Vandevyvere; A Durnez; A Verbruggen; E Geens; F Raeman; R Joos; K de Vlam; V Taelman; J Vanhoof; M Coppens; P Geusens; A Sileghem; P Volders; F Van Den Bosch; P Verschueren; R Westhovens.

Contributors All authors have made substantial contributions to the conception or design of the work; or the acquisition, analysis, or interpretation of data for the work. Futhermore, they drafted the work or revised it critically for important intellectual content and made a final approval of the version to be published. Finally, all authors agree to be accountable for all aspects of the work in ensuring that questions related to the accuracy or integrity of any part of the work are appropriately investigated and resolved.

Funding This RCT was made possible by a Flemish governmental grant (IWT-Innovatie door Wetenschap en Technologie). Patrick Verschueren is supported by a KOF (Klinisch Onderzoeksfonds) grant from the University Hospitals Leuven and holds the Pfizer Chair for Early Rheumatoid Arthritis Management at the KU Leuven.

Competing interests None.

Patient consent Obtained.

Ethics approval The study was approved by the Ethics Committee of the University Hospitals Leuven, and all study patients gave their written informed consent.

Provenance and peer review Not commissioned; externally peer reviewed.

Data sharing statement Further analyses are available upon request from DDC/PV, the corresponding authors at KU Leuven.

\section{REFERENCES}

1 Deighton C, O'Mahony R, Tosh J, et al. Management of rheumatoid arthritis: summary of NICE guidance. BMJ 2009;338:b702.

2 Singh JA, Furst DE, Bharat A, et al. 2012 update of the 2008 American College of Rheumatology recommendations for the use of disease-modifying antirheumatic drugs and biologic agents in the treatment of rheumatoid arthritis. Arthritis Care Res 2012;64:625-39.

3 Smolen JS, Landewe R, Breedveld FC, et al. EULAR recommendations for the management of rheumatoid arthritis with synthetic and biological disease-modifying antirheumatic drugs: 2013 update. Ann Rheum Dis 2013;73:492-509.

4 Verschueren P, Westhovens R. Optimal care for early RA patients: the challenge of translating scientific data into clinical practice. Rheumatology (Oxford) 2011; 50:1194-200

5 Boers M, Verhoeven AC, Markusse HM, et al. Randomised comparison of combined step-down prednisolone, methotrexate and sulphasalazine with sulphasalazine alone in early rheumatoid arthritis. Lancet 1997;350:309-18.

6 Mottonen T, Hannonen P, Leirisalo-Repo M, et al. Comparison of combination therapy with single-drug therapy in early rheumatoid arthritis: a randomised trial. FIN-RACo trial group. Lancet 1999;353:1568-73.

7 Calguneri M, Pay S, Caliskaner Z, et al. Combination therapy versus monotherapy for the treatment of patients with rheumatoid arthritis. Clin Exp Rheumatol 1999:17:699-704.

8 Goekoop-Ruiterman YP, de Vries-Bouwstra JK, Allaart CF, et al. Comparison of treatment strategies in early rheumatoid arthritis: a randomized trial. Ann Intern Med 2007;146:406-15

9 Leirisalo-Repo M, Kautiainen $\mathrm{H}$, Laasonen $\mathrm{L}$, et al. Infliximab for 6 months added on combination therapy in early rheumatoid arthritis: 2-year results from an investigator-initiated, randomised, double-blind, placebo-controlled study (the NEO-RACo Study). Ann Rheum Dis 2013;72:851-7.

10 Horslev-Petersen $\mathrm{K}$, Hetland ML, Junker $\mathrm{P}$, et al. Adalimumab added to a treat-to-target strategy with methotrexate and intra-articular triamcinolone in early rheumatoid arthritis increased remission rates, function and quality of life. The OPERA Study: an investigator-initiated, randomised, double-blind, parallel-group, placebo-controlled trial. Ann Rheum Dis 2014;73:654-61.
11 Landewe RB, Boers M, Verhoeven AC, et al. COBRA combination therapy in patients with early rheumatoid arthritis: long-term structural benefits of a brief intervention. Arthritis Rheum 2002;46:347-56.

12 Korpela M, Laasonen L, Hannonen $\mathrm{P}$, et al. Retardation of joint damage in patients with early rheumatoid arthritis by initial aggressive treatment with disease-modifying antirheumatic drugs: five-year experience from the FIN-RACo study. Arthritis Rheum 2004;50:2072-81.

13 Makinen $\mathrm{H}$, Kautiainen $\mathrm{H}$, Hannonen $\mathrm{P}$, et al. Sustained remission and reduced radiographic progression with combination disease modifying antirheumatic drugs in early rheumatoid arthritis. J Rheumatol 2007;34:316-21.

14 Goekoop-Ruiterman YP, de Vries-Bouwstra JK, Allaart CF, et al. Clinical and radiographic outcomes of four different treatment strategies in patients with early rheumatoid arthritis (the BeSt study): a randomized, controlled trial. Arthritis Rheum 2008;58(2 Suppl):S126-35

15 Verschueren P, Esselens G, Westhovens R. Predictors of remission, normalized physical function, and changes in the working situation during follow-up of patients with early rheumatoid arthritis: an observational study. Scand J Rheumatol 2009;38:166-72

16 van Tuyl LH, Boers M, Lems WF, et al. Survival, comorbidities and joint damage 11 years after the COBRA combination therapy trial in early rheumatoid arthritis. Ann Rheum Dis 2010:69:807-12.

17 O'Dell JR, Curtis JR, Mikuls T, et al. Validation of methotrexate-first strategy in early poor prognosis rheumatoid arthritis: Results from a randomized, double-blind, 2-year trial. Arthritis Rheum 2013;65:1985-94.

18 De Cock D, Vanderschueren G, Meyfroidt S, et al. Two-year clinical and radiologic follow-up of early RA patients treated with initial step up monotherapy or initial step down therapy with glucocorticoids, followed by a tight control approach: lessons from a cohort study in daily practice. Clin Rheumatol 2014;33:125-30.

19 Kirwan JR, Bijlsma JW, Boers M, et al. Effects of glucocorticoids on radiological progression in rheumatoid arthritis. Cochrane Database Syst Rev 2007;(1): CD006356.

20 Hoes JN, Jacobs JW, Buttgereit F, et al. Current view of glucocorticoid co-therapy with DMARDs in rheumatoid arthritis. Nat Rev Rheumatol 2010;6:693-702.

21 Hetland ML, Horslev-Petersen K. The CIMESTRA study: intra-articular glucocorticosteroids and synthetic DMARDs in a treat-to-target strategy in early rheumatoid arhtritis. Clin Exp Rheumatol 2012;30(4 Suppl 73):S44-9.

22 van Tuyl LH, Plass AM, Lems WF, et al. Why are Dutch rheumatologists reluctant to use the COBRA treatment strategy in early rheumatoid arthritis? Ann Rheum Dis 2007:66:974-6.

23 Meyfroidt S, van Hulst LT, De Cock D, et al. Factors influencing the prescription of intensive combination treatment strategies for early rheumatoid arthritis. Scand J Rheumatol 2014:43:265-72.

24 Gorter SL, Bijlsma JW, Cutolo M, et al. Current evidence for the management of rheumatoid arthritis with glucocorticoids: a systematic literature review informing the EULAR recommendations for the management of rheumatoid arthritis. Ann Rheum Dis 2010:69:1010-14.

25 van Vollenhoven RF, Ernestam S, Geborek P, et al. Addition of infliximab compared with addition of sulfasalazine and hydroxychloroquine to methotrexate in patients with early rheumatoid arthritis (Swefot trial): 1-year results of a randomised trial. Lancet 2009:374:459-66.

26 Moreland LW, O'Dell JR, Paulus HE, et al. A randomized comparative effectiveness study of oral triple therapy versus etanercept plus methotrexate in early aggressive rheumatoid arthritis: the treatment of Early Aggressive Rheumatoid Arthritis Trial. Arthritis Rheum 2012;64:2824-35.

27 Combe B, Rincheval N, Benessiano J, et al. Five-year favorable outcome of patients with early rheumatoid arthritis in the 2000s: data from the ESPOIR cohort. J Rheumatol 2013;40:1650-7.

28 Graudal N, Jurgens G. Similar effects of disease-modifying antirheumatic drugs, glucocorticoids, and biologic agents on radiographic progression in rheumatoid arthritis: meta-analysis of 70 randomized placebo-controlled or drug-controlled studies, including 112 comparisons. Arthritis Rheum 2010;62:2852-63.

29 Radner H, Neogi T, Smolen JS, et al. Performance of the 2010 ACR/EULAR classification criteria for rheumatoid arthritis: a systematic literature review. Ann Rheum Dis 2014;73:114-23.

30 Katchamart W, Trudeau J, Phumethum V, et al. Methotrexate monotherapy versus methotrexate combination therapy with non-biologic disease modifying anti-rheumatic drugs for rheumatoid arthritis. Cochrane Database Syst Rev 2010;(4):CD008495. http:/l onlinelibrary.wiley.com/doi/10.1002/14651858.CD008495/abstract

$31 \mathrm{Ma}$ MH, Kingsley GH, Scott DL. A systematic comparison of combination DMARD therapy and tumour necrosis inhibitor therapy with methotrexate in patients with early rheumatoid arthritis. Rheumatology (Oxford) 2010;49:91-8.

32 Tugwell $P$, Pincus T, Yocum D, et al. Combination therapy with cyclosporine and methotrexate in severe rheumatoid arthritis. The Methotrexate-Cyclosporine Combination Study Group. New Engl J Med 1995;333:137-41.

33 Dougados M, Combe B, Cantagrel A, et al. Combination therapy in early rheumatoid arthritis: a randomised, controlled, double blind 52 week clinical trial of sulphasalazine and methotrexate compared with the single components. Ann Rheum Dis 1999;58:220-5. 
34 O'Dell JR, Leff R, Paulsen G, et al. Treatment of rheumatoid arthritis with methotrexate and hydroxychloroquine, methotrexate and sulfasalazine, or a combination of the three medications: results of a two-year, randomized, double-blind, placebo-controlled trial. Arthritis Rheum 2002;46:1164-70.

35 Verschueren P, Esselens G, Westhovens R. Daily practice effectiveness of a step-down treatment in comparison with a tight step-up for early rheumatoid arthritis. Rheumatology (Oxford) 2008;47:59-64.

36 den Uyl D, Ter Wee M, Boers $M$, et al. A non-inferiority trial of an attenuated combination strategy ('COBRA-light') compared to the original COBRA strategy: clinical results after 26 weeks. Ann Rheum Dis 2014;73:1071-8.

37 de Jong PH, Hazes JM, Barendregt PJ, et al. Induction therapy with a combination of DMARDs is better than methotrexate monotherapy: first results of the tREACH trial. Ann Rheum Dis 2013;72:72-8.

38 Grigor C, Capell H, Stirling A, et al. Effect of a treatment strategy of tight control for rheumatoid arthritis (the TICORA study): a single-blind randomised controlled trial. Lancet 2004;364:263-9.

39 Goekoop-Ruiterman YP, de Vries-Bouwstra JK, Kerstens PJ, et al. DAS-driven therapy versus routine care in patients with recent-onset active rheumatoid arthritis. Ann Rheum Dis 2010;69:65-9.

40 van Tuyl LH, Plass AM, Lems WF, et al. Discordant perspectives of rheumatologists and patients on COBRA combination therapy in rheumatoid arthritis. Rheumatology (Oxford) 2008:47:1571-6.

41 Esselens G, Westhovens R, Verschueren P. Effectiveness of an integrated outpatient care programme compared with present-day standard care in early rheumatoid arthritis. Musculoskeletal Care 2009;7:1-16.
42 Meyfroidt S, Van der Elst K, De Cock D, et al. Rheumatologists', nurses' and patients' perceptions of glucocorticoids as a part of initial combination treatment for early rheumatoid arthritis: a qualitative interview study. International Conference for Rheumatology Nurses; 11-12 October 2013; Rotterdam, the Netherlands, 2013.

43 Buttgereit F, da Silva JA, Boers $M$, et al. Standardised nomenclature for glucocorticoid dosages and glucocorticoid treatment regimens: current questions and tentative answers in rheumatology. Ann Rheum Dis 2002;61:718-22

44 Buttgereit F, Straub RH, Wehling M, et al. Glucocorticoids in the treatment of rheumatic diseases: an update on the mechanisms of action. Arthritis Rheum 2004:50:3408-17.

45 Spies CM, Strehl C, van der Goes MC, et al. Glucocorticoids. Best Pract Res Clin Rheumatol 2011;25:891-900.

46 Bakker MF, Jacobs JW, Welsing PM, et al. Low-dose prednisone inclusion in a methotrexate-based, tight control strategy for early rheumatoid arthritis: a randomized trial. Ann Int Med 2012;156:329-39.

47 Haugeberg G, Strand A, Kvien TK, et al. Reduced loss of hand bone density with prednisolone in early rheumatoid arthritis: results from a randomized placebo-controlled trial. Arch Intern Med 2005;165:1293-7.

48 Kirwan JR. The effect of glucocorticoids on joint destruction in rheumatoid arthritis. The Arthritis and Rheumatism Council Low-Dose Glucocorticoid Study Group. New Engl J Med 1995;333:142-6.

49 Aletaha D, Funovits J, Keystone EC, et al. Disease activity early in the course of treatment predicts response to therapy after one year in rheumatoid arthritis patients. Arthritis Rheum 2007;56:3226-35. 